\title{
DUST STORM DETECTION USING MODIS DATA OVER THE MIDDLE EAST
}

\author{
A. Zandkarimi ${ }^{1, *}$, P. Fatehi ${ }^{2}$ \\ ${ }^{1}$ Dept. of Remote Sensing, Tabriz University, Tabriz, Iran- Zandkarimi.Arash@yahoo.com \\ 2 Dept. of Forestry and Forest Economics, Faculty of Natural Resources, University of Tehran, Karaj, Iran- Parviz.Fatehi@ut.ac.ir
}

Commission VI, WG VI/4

KEY WORDS: Detection, Dust, MODIS, Remote sensing, Evaluation, Middle East.

\begin{abstract}
:
Dust storms are one of the common phenomena in the arid and semi-arid regions which cause many economic and environmental losses also affect human health. Therefore, it is necessary to be able to detect dust storms. Several methods exist for dust monitoring, such as Ground-based measurements, satellite remote sensing, video surveillance, wireless sensors. Remote sensing technology provides wide coverage, high spectral and temporal resolutions, even near real-time data, which can offer a valuable data source for dust storm monitoring. We used an algorithm based on Moderate Resolution Imaging Spectroradiometer (MODIS) images for detecting dust storm over the Middle East. The proposed algorithm uses the brightness temperature using multi-bands. The performance of the algorithm was evaluated using the ground-based observations of synoptic stations. The results showed that by applying the algorithm, the dust area can be clearly separated, especially in the regions that cloud is mixed with dust and achieved overall accuracy was $\sim 78 \%$.
\end{abstract}

\section{INTRODUCTION}

Dust storms occur frequently in the windy arid and semi-arid regions (Awad and Mashat 2013, Taghavi et al., 2017). The majority of dust aerosol sources are generated from the west coast of North Africa, the Middle East region, Central and South Asia, and China (Prospero et al. 2002).

Dust storms have a huge impact on the air quality (Gunaseelan et al., 2014), human health (Morabbi, 2011), economic condition (Jafari \& Malekian, 2015), ecosystem services (Singh et al., 2008), and atmospheric radiation (DeMott et al., 2003). Thus, it is crucial to be able to monitor dust storms to reduce dust-caused damages.

Dust storms are the result of the combination of dry conditions and strong wind draws, which in turn raise a large amount of dust from the land into the sky. It makes air quality problems and reduce visibility to less than $1 \mathrm{~km}$ (Samadi et al., 2014). This event occurs commonly and frequently in many parts of the Middle East. In fact, the Middle East is one of the most dust-prone regions with a frequent occurrence of dust storms (Kutiel \& Furman, 2003). In recent decades, there has been a rapid increase in the occurrence of the dust storm in the Middle East. (Khoshakhlagh et al., 2012). The strong wind in this region contributes to the long-range transport of dust, thereby the large parts of the area are affected by dust storms (Shao, 2008).

According to the World Meteorological Organization (WMO) protocol, dust events are classified according to visibility into the following categories: (1) dust in suspension, visibility $>10$ $\mathrm{km}$; (2) blowing dust, $1 \mathrm{~km}<$ visibility $<10 \mathrm{~km}$; (3) dust storm, $200 \mathrm{~m}<$ visibility $<1,000 \mathrm{~m}$; and (4) Sever dust storm, visibility $<200 \mathrm{~m}$ (Shao and Dang 2006).

Due to the high spatial variability of dust occurrence make the in-situ measurement limited, however, satellite remote sensing technology, which has a high temporal and spatial monitoring capability, becomes an effective tool for dust storm survey (Kaufman et al., 2002; Al-Dousari et al., 2017). In particular, many previous studies have used Moderate Resolution Imaging Spectroradiometer (MODIS) imagery for dust detection (Zhang et al., 2008; Jafari and Malekian, 2015; Butt \& Mashat, 2018). Numerous researchers have explored different MODIS spectral wavelengths such as, the Infra-red (IR) wavelengths (e.g. Wald et al. 1998; She et al., 2018) or a combination of visible and infrared spectral bands (e.g. Shenk and Curran 1974;Samadi et al. 2014; Albugami et al., 2018) to detect dust storm. As a result, the less attention is given to the longer wavelength for mapping dust storm therefore, in this study the dust detection algorithm using thermal infrared channels is explored.

In this paper, a dust detection algorithm based on Moderate Resolution Imaging Spectroradiometer (MODIS) over the Middle East region is proposed. Additionally, 211 synoptic stations covering a 1-year time period is used for validating the reliability of the algorithm. The suggested algorithm has resolved the limitation to the common issues reported by previous studies (i.e. Problems with seasonal changes and with dust discrimination from other objects like clouds).

\section{DATA AND STUDY AREA}

\subsection{STUDY AREA}

The study region is composed of a major part of the Middle East, i.e., Iraq, Syria, Jordan, Iran, Saudi Arabia and Turkey. Basically, it is one of the largest dust sources in the world. Most of these areas are located in the semi-arid and arid region and have many deserts (figure 1). 


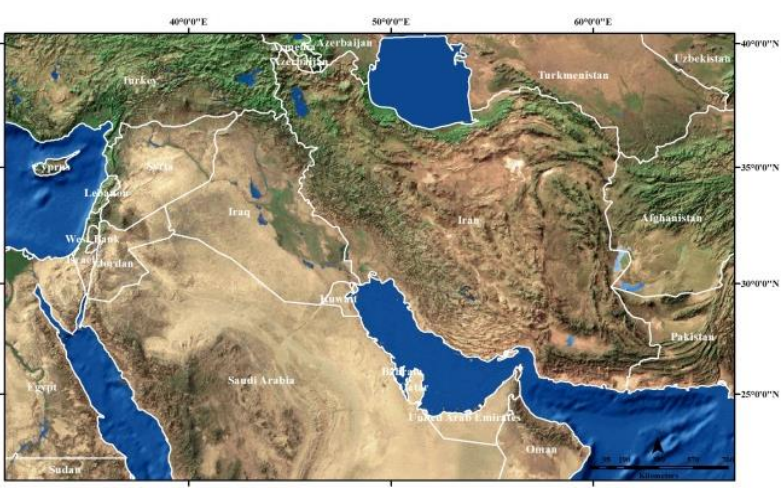

Figure 1. Study region

\subsection{DATA}

The MODIS images and Ground-based measurements data were used for detecting the dust storms and validating the results of the proposed algorithm.

MODIS was successfully launched on-board as a part of the NASA Earth Observing System (EOS) mission. Terra and Aqua satellites allow acquiring images in 36 spectral channels with spatial resolutions of $250 \mathrm{~m}, 500 \mathrm{~m}$, and $1 \mathrm{~km}$ at nadir. These satellites launched in December 1999 and May 2002, respectively (Zhang et al., 2008). Additional information, i.e., the visibility data and code 06 were obtained from 212 synoptic stations over the Iranian territory by the Islamic Republic of Iran Meteorological Organization (IRIMO). This was due to a limitation on the access to synoptic station data of other countries.

\section{METHOD}

The dust identification approach is based on the brightness temperature in three channels. The brightness temperature was calculated from radiance data by the inversion of Plank's law (Equation 1).

$$
B_{\lambda}(T)=\frac{2 h c^{2}}{\lambda^{5}\left[\exp \left(\frac{c h}{k \lambda t}\right)-1\right]}
$$

Where B $(T, \lambda)$ is the spectral radiance in the absolute temperature of the black body $(T)$ at the specific wavelength $(\lambda)$, $" h "$ is the Plank's constant $\left(6.62607004 \times 10^{-34} \mathrm{~J} \mathrm{~s}\right), " c "$ is the speed of light and " $k$ " is the Boltzmann's constant (Taghavi et al., 2017).

For a gray body, the spectral radiance is a section of the black body radiance, defined by the emissivity $\varepsilon$. That makes the reciprocating of the brightness temperature.

$$
T=\frac{h c}{\lambda_{i} k \ln \left(\frac{2 h c^{2}}{L\left(\lambda_{i}\right) \lambda_{i}^{5}}\right)+1}
$$

The statistical metrics, i.e., the mean and standard deviation of training pixels have been calculated, which in turn used as a threshold value. Different thresholds were determined for the relevant classes (i.e. water, dust, and land). Firstly, the water pixels from land surface pixels have been separated. To identify and remove the clouds the equation (3) was applied:

$$
\mathrm{BT}_{32}=\mathrm{BT}_{32} \text { gt } 270
$$

Where $\mathrm{BT}_{32}$ represent the brightness temperature at $12.02 \mu \mathrm{m}$. The threshold temperature of $270 \mathrm{~K}$ was used.

Over the dust area, the brightness temperature of band 20 typically has a higher forward scattering than band 31, therefore, the difference between two bands can be used as in indicator to retrieve dust density (Equation. 4).

$$
\mathrm{BT}_{20.31}=\mathrm{BT}_{20}-\mathrm{BT}_{31}
$$

Where, B20 and B31 represent the brightness temperature at 37.5 and $11.3 \mu \mathrm{m}$, respectively. The BTD threshold of 17 is used to separate dust from other classes.

\subsection{Validation}

A long-term evaluation procedure was implemented to test the capability of the proposed approach. The generated maps were compared with yearly field measurement, i.e. The visibility data and code 06 from 2016 to 2018 (table 1). The field data obtained from the synoptic stations over the Iran territory by the IRIMO (figure 2). In this paper, the events of 12 July 2017 and 19 Jan 2018 are validated. A discrete method (binary yes/no) approach was used For validating the generated maps (Eq. 5). In equation (5), the variable " $a$ " represents true positives, both synoptic data and the algorithms show the presence of "dust". The variable " $b$ " represents false positives, the number of times where synoptic data shows "no dust," but the algorithm shows "dust"; the variable " $c$ " represents false negatives, the number of times where synoptic data indicates "dust," but the algorithm indicates "no dust"; the variable " $d$ " represents true negatives, the number of times where both synoptic data and the algorithms show "no dust" (Ciren and Kondragunta, 2014).

$$
\text { Accuracy }=\frac{a+d}{a+b+c+d} \times 100
$$

A flowchart of the methodology applied in this paper is shown in Figure 3.

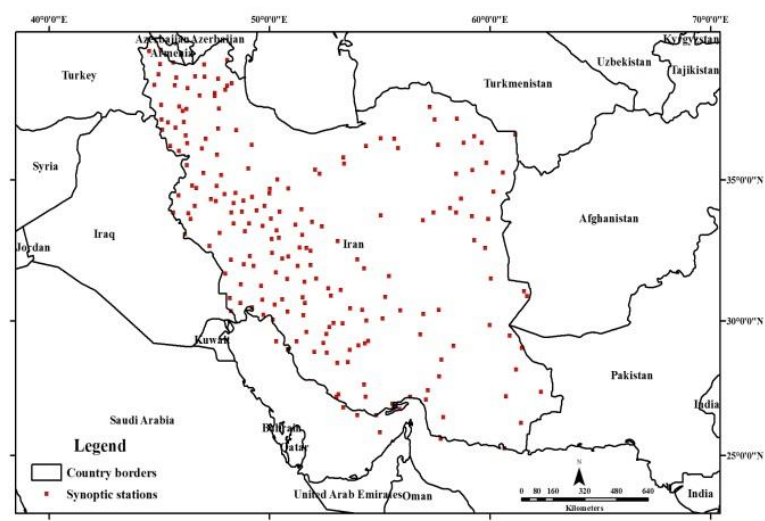

Figure 2. Distribution of 212 synoptic stations utilized in this study 


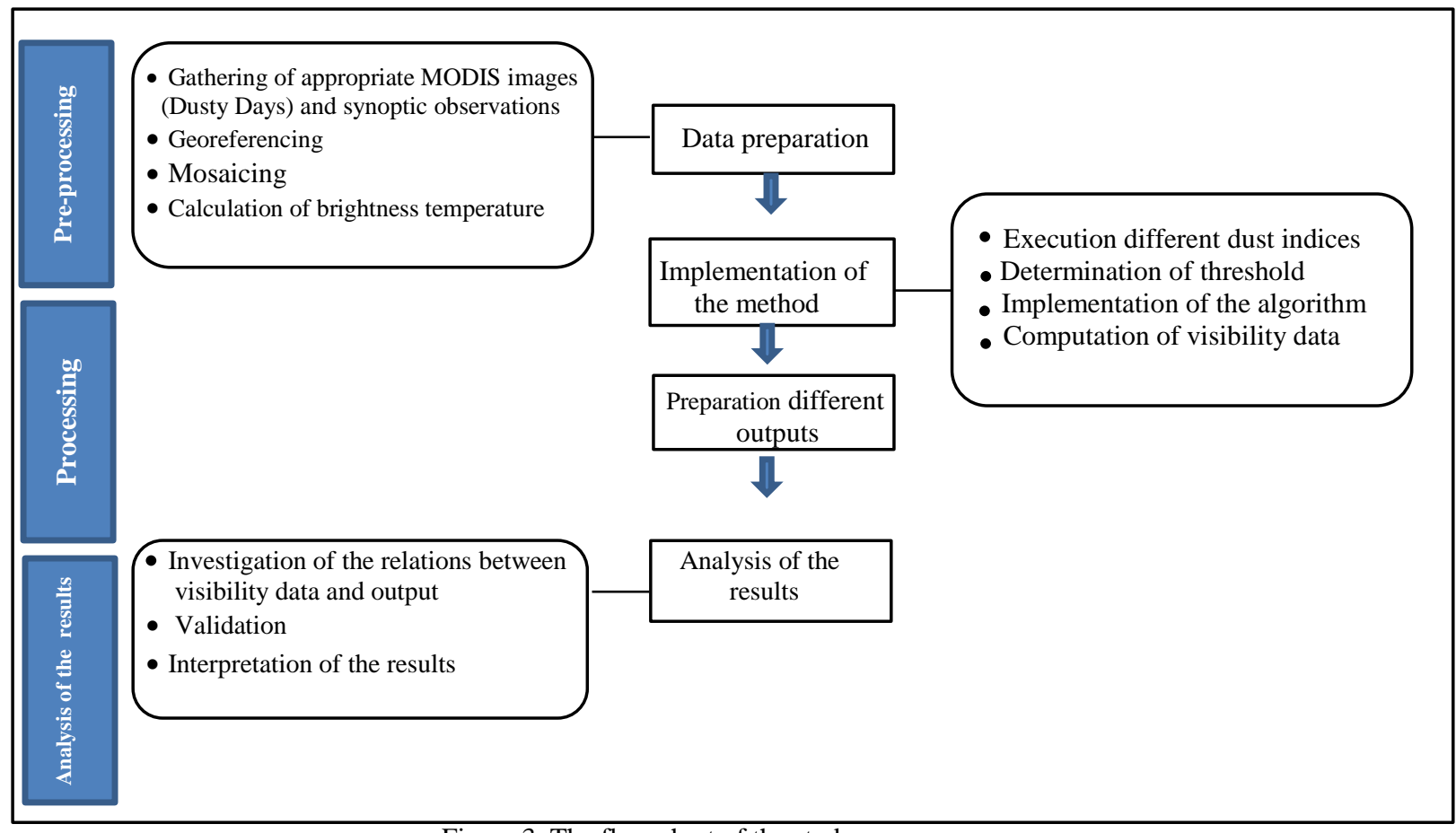

Figure 3. The flow chart of the study

\section{RESULTS AND DISCUSSIONS}

In this study, MODIS satellite imagery was used for detecting dust storm events over the Middle East. We focused on using the thermal infrared channel to develop an algorithm with a minimum false. In order to evaluate the proposed algorithm ground observations were obtained from the synoptic stations. Figure 4 indicates the dust detection results in which dust pixels are shown in red color. Figure $4(" b "$ and " $d ")$ shows that the dust storm is mixed with the clouds. As shown the dusty areas were clearly distinguished by applying the proposed approach (Figure 4 (" $a$ " and " $c$ " images)). The quantitative validation of detected areas based on the ground-based observations is shown in Table 1. It is important to mention that the difference time between MODIS data acquisition and Ground-based observations were less than $20 \mathrm{~min}$.
Table 1. The result of Validation

\begin{tabular}{|c|c|}
\hline ID & Accuracy \\
\hline The proposed algorithm & $78 \%$ \\
\hline
\end{tabular}

As shown in Table 1, the accuracy is $\sim 78 \%$. 


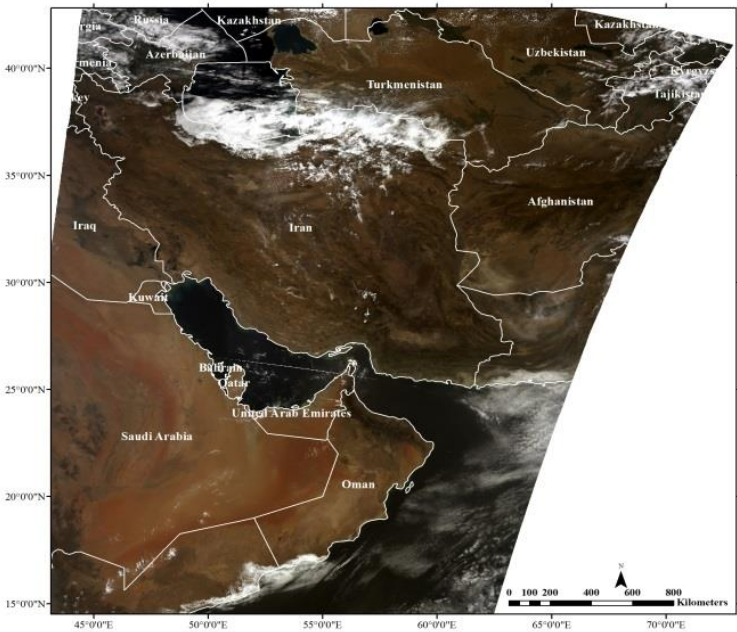

(a)

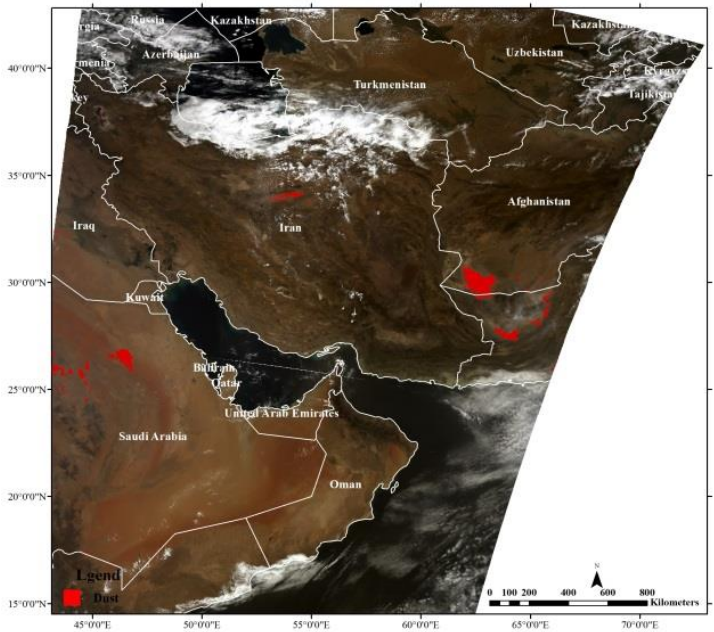

(b)

2017/07/12

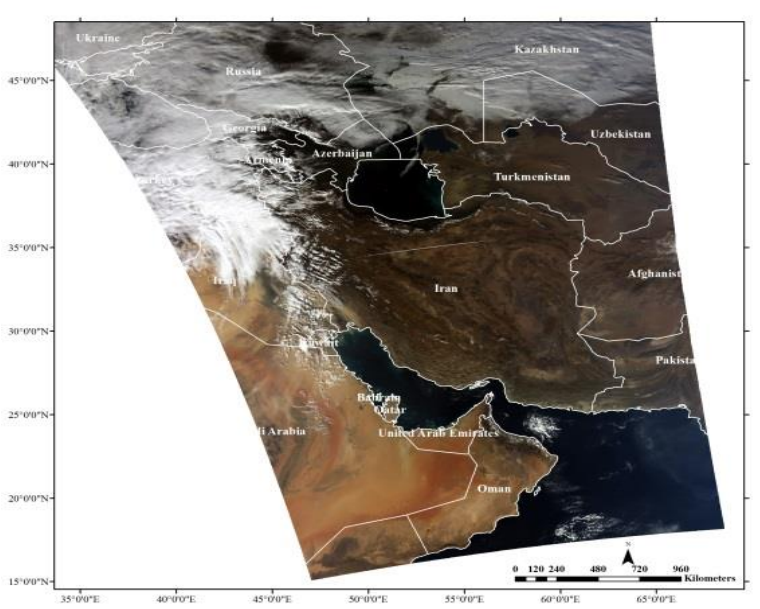

(c)

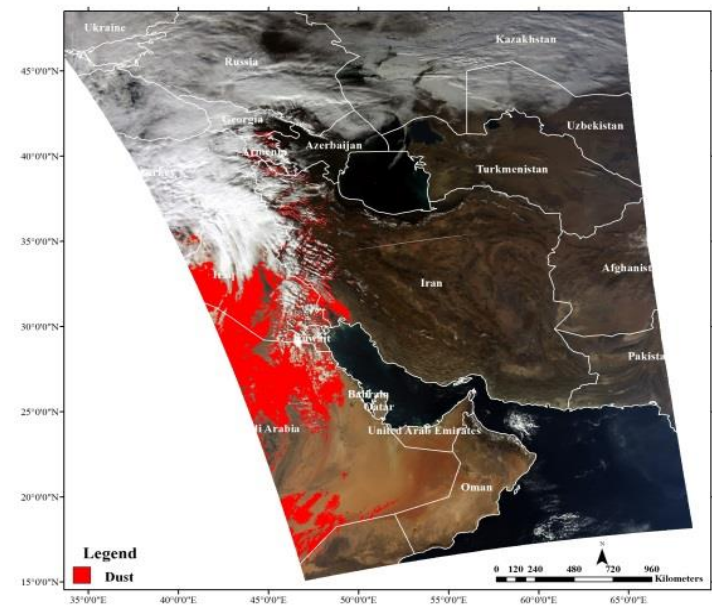

(d)

\section{8/01/19}

Figure 4. MODIS true color images ("a" and "c") The results of the proposed algorithm ("b" and "d")

\section{CONCLUSION}

The proposed approach showed an improvement to detect dust storms over the middle east. The algorithm in this study has been validated by the synoptic situations (The visibility data and code 06 ). The results showed that the accuracy is $78 \%$. By using the proposed algorithm the dust area was clearly separated and indicated a good agreement with the ground-based observation, but further studies should be done in the future in order to identify dust storm, particularly, over the water area in the Middle East.

The results of the study will be applicable for the decisionmakers and planner (such as the Department of Environment, The Iranian space agency, etc).

\section{REFERENCES}

Awad, A.M., Mashat, A.W.S., 2013. Synoptic features associated with dust transition processes from North Africa to Asia. Arab J Geosci, 7(6),10.1007/s12517-013-0923-4.

Al-Dousari, A.M., Al-Awadhi, J., Ahmed, M., 2013. Dust fallout characteristics within global dust storm major trajectories. Arab J Geosci, 6(10), 3877-3884, 10.1007/s12517012-0644-0.

Albugami, S., Palmer, S., Meersmans, J and Waine, Toby (2018). Evaluating MODIS Dust-Detection Indices over the Arabian Peninsula. Remote Sens, 10 (12), 1-17, $10.3390 / \mathrm{rs} 10121993$.

Butt, M.J and Mashat, A.S. (2018). MODIS satellite data evaluation for sand and dust storm monitoring in Saudi Arabia, International Journal of Remote Sensing, 1-20, DOI: 10.1080/01431161.2018.1488293.

Ciren, P., and S. Kondragunta (2014), Dust aerosol index (DAI) algorithm for MODIS, J. Geophys. Res. Atmos., Vol: 119, 4770-4792, DOI: 10.1002/2013JD020855. 
DeMott, P. J., Sassen, K., Poellot, M., Baumgardner, D., Rogers, D. C., Brooks, S., Prenni, A.J and Kreidenweis, S.M (2003). African dust aerosols as atmospheric ice nuclei. Geophysical Research Letters, $30 \quad(14), \quad 1-4$, 10.1029/2003GL017410.

Gunaseelan, I., B. V. Bhaskar, and Muthuchelian K.. 2014. The Effect of Aerosol Optical Depth on Rainfall with Reference to Meteorology over Metro Cities in India, Environmental Science and Pollution Research, 21 (13), 8188-8197. 10.1007/s11356014-2711-4.

Jafari, R., Malekian, M., 2015. Comparison and evaluation of dust detection algorithms using MODIS Aqua/Terra Level 1B data and MODIS/OMI dust products in the Middle East. International Journal of Remote Sensing. 36 (2), 597-617, https://doi.org/10.1080/01431161.2014.999880.

Kaufman, Y.J., Tanre, D., Boucher, O., 2002. A satellite view of aerosols in the climate system. Nature. 419, 215-223, 10.1038/nature01091.

Kutiel, H and Furman, H., (2003). Dust storms in the Middle East: Sources of origin and their temporal characteristics. Indoor Built Environment, 12 (6), 419-426. https://doi.org/10.1177\%2F1420326X03037110.

Khoshakhlagh, F., Najafi, M.S., Samadi, M., 2012. An analysis on synoptic patterns of springtime dust occurrence in West of Iran. Physical Geography Research Quarterly, 44 (2), 99-124.

Morabbi, M., 2011. Risk warning and crisis management for dust storm effects on western border of Iran. United Nations International Conference on Space-based Technologies for Disaster Risk Management. Beijing, China.

Prospero, J. M., Ginoux, P., Torres, O., Nicholson, S. E., Gill, T. E., 2002. Environmental Characterization of Global Sources of Atmospheric Soil Dust Identified with the Nihpaus 7 Total Ozone Mapping Spectrometer (TOMS) Absorbing Aerosol Product. Review of Geophysics, 40 (1).10.1029/2000RG000095.

Samadi, M., Darvishi Boloorani, A., Alavipanah, S.K., Mohamadi, H., Najafi, M. S., 2014. Global dust Detection Index (GDDI); a new remotely sensed methodology for dust storm detection. $J$ Environ Health Sci Eng, 12 (1), 1-14, 10.1186/2052-336X-12-20.

Shao, Y., 2008. Physics and modelling of wind erosion (2nd edn.). Heidelberg: Springer. ISBN: 978-1-4020-8895-7, 1-458, doi: 10.1007/978-1-4020-8895-7.

Shao, Y and Dong C.H., 2006. A review of East Asian dust storm, climate, modelling and monitoring, Global and Planetary Change, Vol: 52, Pp: 1-22.

She, L., Xue, Y., Yang, Xi., Guang, J., Li, Y., Che, Y., Fan, Ch ., Xie, Y., 2018. Dust Detection and Intensity Estimation Using Himawari-8/AHI Observation. Remote Sens. 10 (4), 1-20, $10.3390 /$ rs 10040490 .

Shenk, W.E., Curran, R.J., 1974. The detection of dust storms over land and water with satellite visible and infrared measurements. Mon Weather Rev, 102, https://doi.org/10.1175/1520 0493(1974)102<0830:TDODSO>2.0.CO;2.

Singh, R. P., Prasad, A. K., Kayetha, V. K., and Kafatos, M., 2008. Enhancement of oceanic parameters associated with dust storms using satellite data. Journal of Geophysical Research, 113, 1- 13, https://doi.org/10.1029/2008JC004815.

Taghavi, F., Owlad, E. \& Ackerman, S.A., 2017. Enhancement and identification of dust events in the south-west region of Iran using satellite observations. J Earth Syst Sci. 126 (28). 1-17. https://doi.org/10.1007/s12040-017-0808-0.

Wald, AE., Kaufman, Y.J., Tanre, D., Gao, B.C., 1998. Daytime and nighttime detection of mineral dust over desert using infrared spectral contrast. J Geophys Res, 103 (D24), 3230732313, https://doi.org/10.1029/98JD01454.

Zhang, B., Tsunekawa, A., Tsubo, M., 2008. Contributions of sandy lands and stony deserts to long-distance dust emission in China and Mongolia during 2000-2006. Global and Planetary Change, 60, 487-504, http://dx.doi.org/10.1016/j. 